\title{
ASSESSMENT OF ELECTRIC POTENTIAL GENERATED DURING LIGHTNING STRIKE BY FINITE ELEMENT METHOD
}

\author{
${ }^{1}$ Larisa MARIUT, ${ }^{2}$ Elena HELEREA \\ Department of Electrical Engineering and Applied Physics, Electrical Engineering and \\ Computer Science Faculty, Transilvania University of Brasov, 29 Eroilor Str, RO-500036, \\ Brasov, Romania, e-mail: 'elena-larisa.mariut@unitbv.ro, ${ }^{2}$ helerea@unitbv.ro
}

Received 26 July 2015; accepted 17 December 2015

\begin{abstract}
The main effect of lightning is the induced surge voltage within power networks. The paper deals with the assessment of electric potential generated during lightning. A time domain simulation using Finite Element Method was done, considering that the lightning current flows within a discharge channel with variable lengths $(15-91 \mathrm{~m})$ and impedances, having various peaks $(2.5-40 \mathrm{kA})$. Both $8 / 20 \mu \mathrm{s}$ and $5 / 320 \mu$ s lightning current wave shapes have been considered. The surge voltage waveforms were determined for each lightning current. The assessment of electric potential generated during lightning through phase wire, in soil and near underground power cable was done.
\end{abstract}

Keywords: Boundary conditions, Electric potential, Finite element method, Lightning strike, Surge voltage

\section{Introduction}

Power networks are affected by electromagnetic interferences, especially during transient states [1]-[4]. Electromagnetic disturbances [5] generated by indirect/direct lightning strikes may cause, through galvanic/inductive/capacitive couplings, faults in the electrical network [6]-[9]. Many studies [10]-[15] deal with the complex evaluation of lightning through high voltage networks by time-domain analysis, but few of them are directed through the assessment of lightning effects on medium and low voltage networks [16]-[20]. New studies are required for taking into account the effects generated by lightning in the electric distribution power system.

The paper focuses on the following objectives: 
1) To highlight the dependency of lightning surge wave shape on the electric potential distribution near overhead and underground power lines;

2) To underline the dependency of the ground potential rise on the peak lightning current and soil resistivity.

The simulations are done for a particular structure of an overhead distribution line near which an underground power cable is installed.

\section{Lightning strike model and parameters}

\subsection{Induced voltages by lightning currents}

If a lightning current flows through conductive components of power networks, the distribution of the electric potential is influenced by the electric current and impedances of each component [21]. Thus, if the current flows through a single point on a homogeneous conducting surface, the electric potential $V$ rises, with a specific $r$, meaning the distance from the point of strike. The same effect occurs when lightning hits the homogeneous ground (Fig. 1a) [22].

The slope $\Delta i / \Delta t$ of the lightning current wave is connected with the amplitude of the induced voltage, in all conductors through which lightning current flows [23]. Fig. $1 b$ shows the wave voltage $U$ induced during the time interval $\Delta t$ [21]. The current waveform of $8 / 20 \mu \mathrm{s}$, is considered according [22]-[23] for tests and this lightning current may lead to conventional voltage waveform like $1.2 / 50 \mu \mathrm{s}$.

\subsection{Mathematical model of the lightning current}

The mathematical model of the lightning current $i_{\text {surge }}(t)$ is described by the Heidler function

$$
i_{\text {surge }}(t)=k_{i} \cdot\left[\frac{I_{p}}{k_{\text {surge }}} \cdot \frac{\left(t / \tau_{1}\right)^{\eta_{\text {surge }}}}{1+\left(t / \tau_{1}\right)^{\eta_{\text {surge }}}} \cdot e^{-t / \tau_{2}}\right] \text {, }
$$

where $k_{i}$ is current correction coefficient; $\tau_{1}, \tau_{2}$ are rise and fall time of the pulse; $\eta_{\text {surge }}$, $k_{\text {surge }}$ are wave shape correction coefficients; $I_{p}$ is the peak value of the surge current.

The function (1) describes a lightning pulse [24] and $k_{\text {surge }}$ is strongly dependent on the parameters of the wave lightning pulse:

$$
k_{\text {surge }}=\exp \left[-\frac{\tau_{1}}{\tau_{2}} \cdot\left(\frac{\eta_{\text {surge }} \cdot \tau_{2}}{\tau_{1}}\right)^{1 / \eta_{\text {surge }}}\right] .
$$




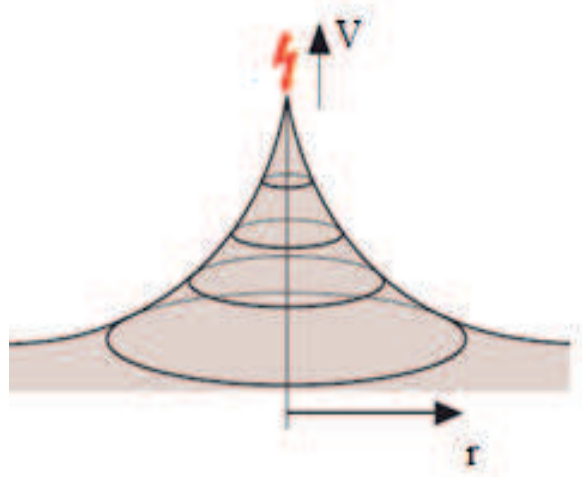

a)

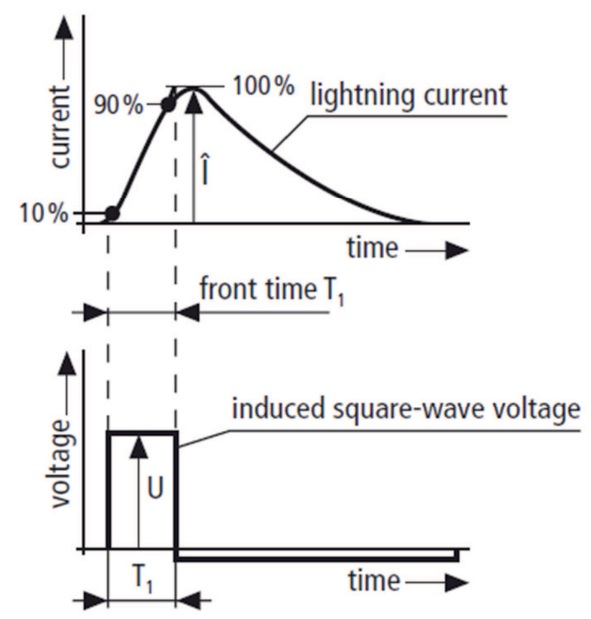

b)

Fig. 1. Lightning strike effect

a) Potential distribution of a lightning strike into homogenous soil; b) Induced square-wave voltage in loops via the current steepness $\Delta i / \Delta t$ of the lightning current

The parameters for different lightning current wave shapes, according to IEC 610004-5:2013, are presented in Table I [23]-[24].

\section{Table I}

Parameters of lightning current wave shape

\begin{tabular}{|l|c|c|c|c|}
\hline Test type & $k_{\mathrm{i}}$ & $\eta_{\text {surge }}$ & $\tau_{1}[\mu \mathrm{s}]$ & $\tau_{2}[\mu \mathrm{s}]$ \\
\hline Surge current $8 / 20 \mu \mathrm{s}$ & 1 & 2.741 & 47.52 & 4.296 \\
Surge current $5 / 320 \mu \mathrm{s}$ & 1 & 1.556 & 1.355 & 429.1 \\
\hline
\end{tabular}


As it is specified in [23], the front time of the lightning current shape is about $8 \mu \mathrm{s}$, and the duration is around $20 \mu \mathrm{s}$.

The lightning discharge channel is equivalent to a copper channel with cross section of $S=7.85 \cdot 10^{-3} \mathrm{~m}^{2}$, outer diameter of $d=0.1 \mathrm{~m}$, with different lengths $L$ and impedances $Z$, according to peak value of the lightning current $I_{p}$ [17]. In Table II the parameters of the lightning channel are given for various lightning strike cases (LS1 LS2), considering that channel length has a strong influence on the lightning current.

Table II

Parameters of lightning channel

\begin{tabular}{|c|c|c|}
\hline Lightning strike cases & $I_{p}[\mathrm{kA}]$ & $L[\mathrm{~m}]$ \\
\hline LS1 & 2.5 & 15 \\
LS2 & 6.5 & 27 \\
LS3 & 13 & 45 \\
LS4 & 40 & 91 \\
\hline
\end{tabular}

Each lightning strike case was applied for both lightning current wave shapes $(8 / 20 \mu \mathrm{s}$ and $5 / 320 \mu \mathrm{s})$, according to [23]. Based on the mathematical description of the Heidler function (1), considering the lightning channel parameters corresponding to each lightning strike case (Table II), the lightning currents wave shapes are obtained (Fig. 2a-Fig. 2b).

The $8 / 20 \mu \mathrm{s}$ wave is applied during testing of low voltage lightning protection equipment.

\subsection{Mathematical model of the surge voltage}

The surge voltage model is obtained based on Ohm's law [21]

$$
u_{\text {surge }}(t)=k_{v} \cdot\left[\frac{U_{p}}{k_{\text {surge }}} \cdot \frac{\left(t / \tau_{1}\right)^{\eta_{\text {surge }}}}{1+\left(t / \tau_{1}\right)^{\eta_{\text {surge }}}} \cdot e^{-t / \tau_{2}}\right]
$$

where, the values of the voltage wave shape parameters (Table III) are specified in [23]-[24].

Table III

Parameters of voltage surge wave shape

\begin{tabular}{|l|c|c|c|c|}
\hline Test type & $k_{\mathrm{v}}$ & $\eta_{\text {surge }}$ & $\tau_{1}[\mu \mathrm{s}]$ & $\tau_{2}[\mu \mathrm{s}]$ \\
\hline Surge voltage $1.2 / 50 \mu \mathrm{s}$ & 1 & 1.852 & 0.356 & 65.845 \\
Surge voltage $10 / 700 \mu \mathrm{s}$ & 1 & 1.556 & 1.355 & 429.1 \\
\hline
\end{tabular}




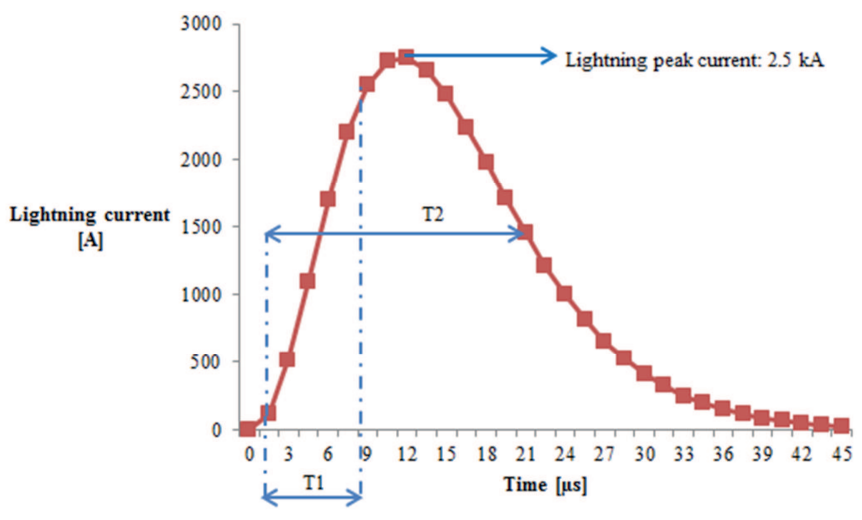

a)

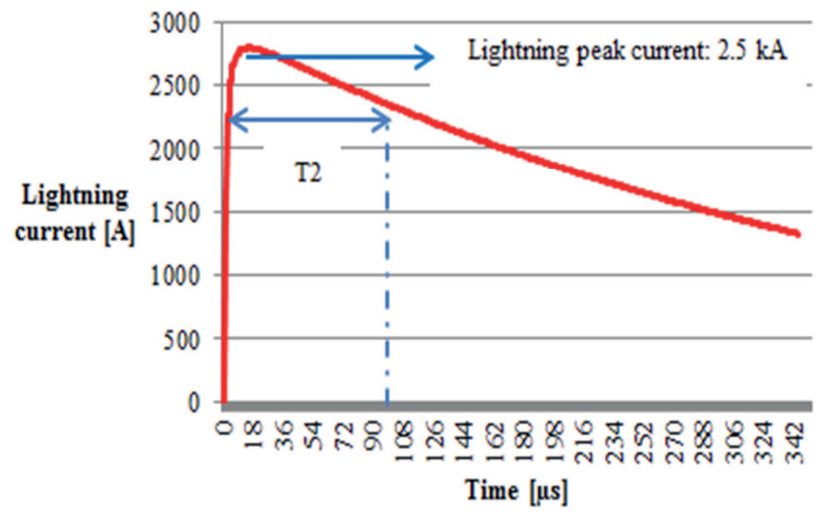

b)

Fig. 2. Lightning current wave shapes corresponding to various $\tau_{1} / \tau_{2}$, a) $8 / 20 \mu \mathrm{s} ;$ b) $5 / 320 \mu \mathrm{s}$

Thus, for each lightning strike case, the surge voltage variations have been obtained (Fig. 3a-Fig. 3b), considering the peak amplitude of the lightning current and the impedance of the conductive component the current flows through.

For each lightning current wave an equivalent surge voltage could be obtained as per IEC 61000-4-5: $8 / 20 \mu \mathrm{s}$ surge current is equivalent to $1.2 / 50 \mu \mathrm{s}$ surge voltage and $5 / 320 \mu$ s surge current is equivalent to $10 / 700 \mu$ s surge voltage.

\section{Assessment of lightning strike effect propagation and FEM simulations}

\subsection{Effects of surge wave propagation - A case study}

It is considered that the lightning strike hits the ground wire of a $20 \mathrm{kV}$ overhead power line and the generated surge wave propagates through tower structure to a 
surrounding underground power network. It is supposed that fault currents of large magnitude, generated during lightning strike, flow through the earth connection of the underground network and the electric potential of the grounding raises. The effects caused by lightning studied hereafter, are presented in Fig. 4.

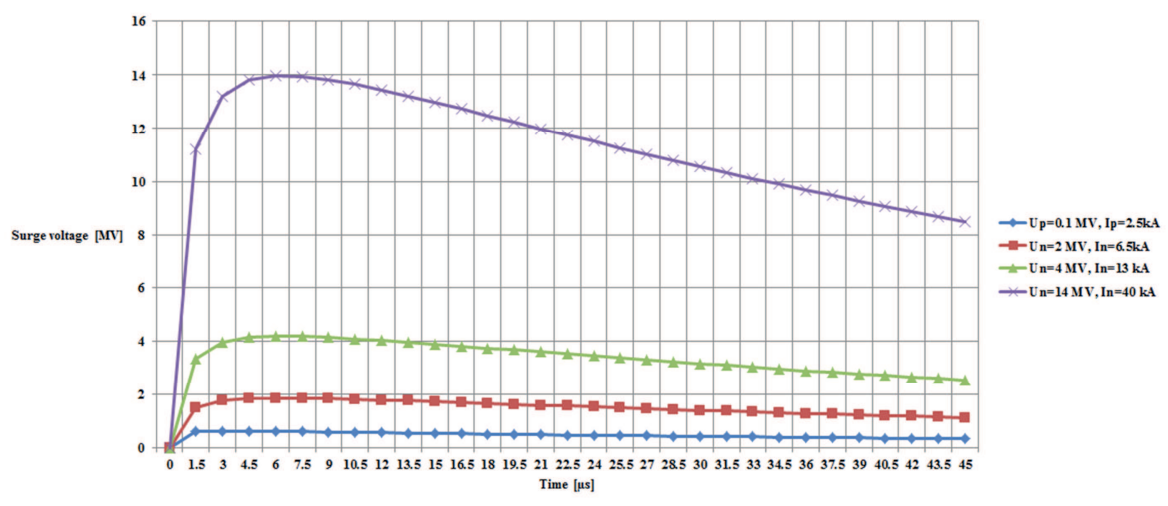

a)

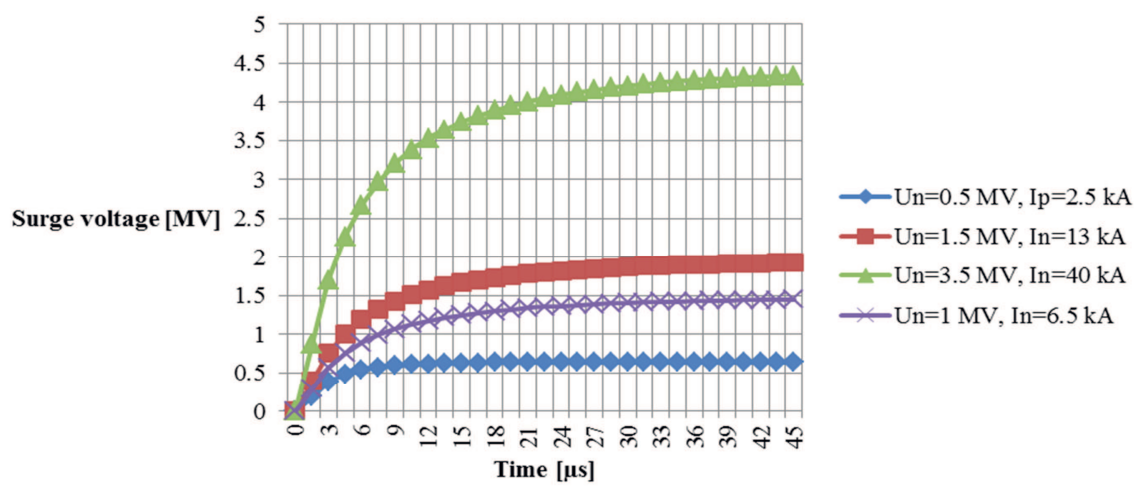

b)

Fig. 3. Surge voltage according to IEC 61000-4-5: a) 1.2/50 $\mu$ s; b) 5/320

The lightning current flows through the tower structure/ground wire of the power line to earth, generating an electric potential: through phase wires of the power line (EP1 case), in soil near tower (EP2 case), and nearby underground cable (EP3 case). The concrete foundation of the tower is neglected.

The case study is performed for a three-phase overhead power line with parameters given in Table $I V$. 


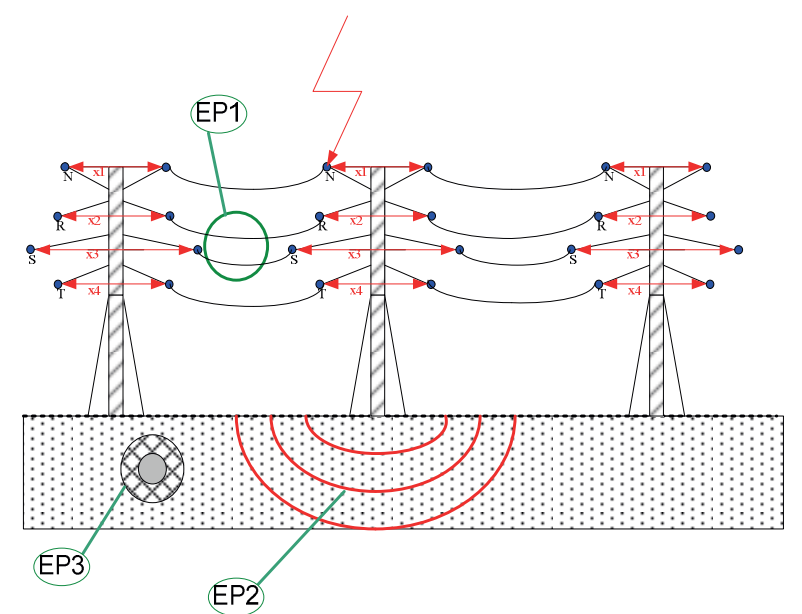

Fig. 4. Lightning strike and the effects of surge wave propagation

Table IV

Medium voltage overhead power line

\begin{tabular}{|l|c|c|c|c|c|c|}
\hline Item & Type & $\begin{array}{c}S \\
{\left[\mathrm{~mm}^{2}\right]}\end{array}$ & Structure & $\begin{array}{c}D_{\mathrm{o}} \\
{[\mathrm{mm}]}\end{array}$ & $\begin{array}{c}R_{l} \\
{[\Omega / \mathrm{km}]}\end{array}$ & $\begin{array}{c}I_{\max } \\
{[\mathrm{A}]}\end{array}$ \\
\hline $\begin{array}{l}\text { Phase } \\
\text { conductor }\end{array}$ & $50 / 8$ & 56.3 & $\begin{array}{c}6 \text { wires of Al } \varnothing 3.20 \mathrm{~mm} \\
+1 \text { wire of Ol } \varnothing 3.20 \mathrm{~mm}\end{array}$ & 9.6 & 0.5946 & 302 \\
\hline
\end{tabular}

According to Fig. 5, the following elevations are considered: $d_{1}=0.7 \mathrm{~m}, d_{2}=1.4 \mathrm{~m}$, $d_{3}=2.2 \mathrm{~m}, d_{4}=1.4 \mathrm{~m}, d_{5}=1 \mathrm{~m}, h_{1}=0.6 \mathrm{~m}, h_{2}=0.5 \mathrm{~m}, h_{3}=0.5 \mathrm{~m}, h_{4}=3 \mathrm{~m}, h_{5}=0.8 \mathrm{~m}$, $h_{6}=0.2 \mathrm{~m}, h_{7}=0.8 \mathrm{~m}$.

The soil resistivity was assumed $100 \Omega \mathrm{m}$ and the relative permittivity of the insulation of power cable and soil is $\varepsilon_{r}=3$ [21].

The installation depth of then underground cable is $-0.8 \mathrm{~m}$, at $1 \mathrm{~m}$ away from the tower structure. The cable is unshielded with unipolar cooper conductor $\left(6 \mathrm{~mm}^{2}\right.$ cross section), and polyethylene insulation, being supplied by a $20 \mathrm{kV}$ AC voltage.

\subsection{Simulation with finite element method}

Finite Element Method (FEM) comprises methods for connecting many simple element equations over many small subdomains, named finite elements, to approximate a more complex equation over a larger domain. This method is used to find approximate solutions to different boundary problems based on Maxwell's solving, being used in many engineering applications.

FEM was applied using Comsol Multiphysics and the AC/DC [25] module was used for a 2D Geometry design, within a Time Domain Simulation. For each lightning strike case, the analysis is performed considering that both the overhead and the underground 
power lines of $20 \mathrm{kV} \mathrm{AC}$, have the parameters of the lightning strikes described in Table II, for $8 / 20 \mu$ s and $5 / 320 \mu$ s lightning current wave shapes.

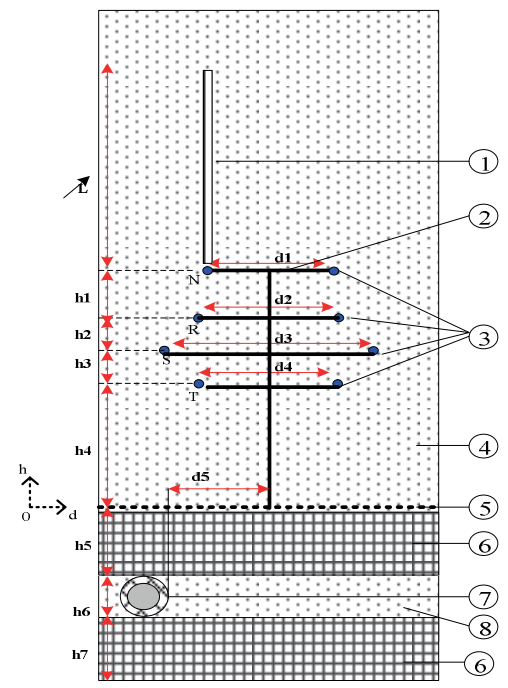

Fig. 5. Front view of the tower structure with the transversal displacement of the underground power cable: 1-Lightning channel; 2-Tower structure; 3-Overhead power line phases (R,S,T, ground wire-N); 4-Air; 5-Ground reference; 6-Soil; 7-Underground power cable; 8-Sand

A triangular mesh was applied (56785 triangular elements, 4077 edge elements and 118 vertex elements). The boundary conditions were established according to the electrostatics interface, as for a quasi-static analysis: equations (4) and (5) for Charge conservation; equation (6) for zero charge; equation (7); equation (8) for electric potential; equation (9) for ground.

$$
\begin{aligned}
& \nabla \cdot\left(\varepsilon_{0} \varepsilon_{r} \cdot E\right)=\rho V, \\
& E=-\nabla \cdot V .
\end{aligned}
$$

The charge conservation describes the macroscopic properties of the medium, relating the electric displacement $\boldsymbol{D}$ with the electric field intensity $\boldsymbol{E}$. The charge conservation boundary was applied for the entire model of the simulation geometry (Fig. 6a). The zero charge condition imposes zero charge on the boundary, so that:

$$
-\boldsymbol{n} \cdot \boldsymbol{D}=0
$$

This is the default boundary condition at exterior boundaries. At interior boundaries, it means that no displacement field can penetrate the boundary and that the electric 
potential is discontinuous across the boundary. The zero charge boundary condition was applied for the entire model of the simulation geometry according to Fig. 6 .

$$
V_{0}=V_{i}(t)
$$

The boundary condition $V=V_{0}$, where $V_{0}$ is being provided. Various boundary conditions of $V_{i}$ were established, as for the conductors of the overhead/underground lines and for the lightning surge that propagates during strike, like: for the overhead and underground conductors of the power lines, AC voltage waveforms were applied according to the working voltage range. For the lightning channel, the surge voltage waveforms previously described were considered. The zero ground boundary condition was applied for the ground reference, ground wire of the overhead power line and for the sheath of the underground power line (Fig. 6c).

$$
\begin{aligned}
& V=0, \\
& \boldsymbol{n} \cdot \boldsymbol{J}=0 .
\end{aligned}
$$

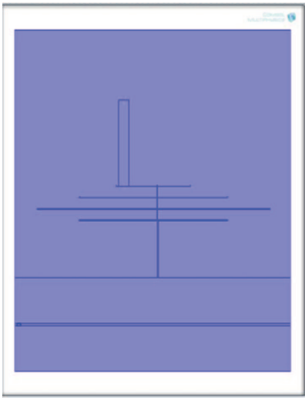

a

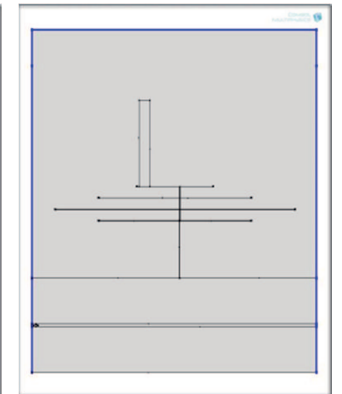

b)

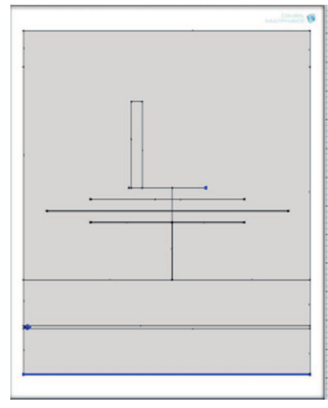

c)

Fig. 6. Boundary conditions, a) Charge conservation; b) Zero charge; c) Ground

Electric insulation boundary is used to model a thin sheet of a resistive material, connected to a reference potential $V_{\text {ref }}$. This condition imposes that no electric current flows into the boundary. It was applied for the underground power cable.

\section{Results and discussions}

\subsection{Dependency of lightning surge wave shape on the electric potential distribution}

The results refer to the distribution of the electric potential for EP1, EP2, EP3 locations (Fig. 1).

In Fig. 7 the electric potential distribution for $8 / 20 \mu$ s lightning current waves is shown, where: 1 is the lightning channel $(15 \mathrm{~m}) ; 2$ is the tower structure; $3,4,5$ are the 
phase R, S, T wires of the $20 \mathrm{kV}$ overhead power line, 6 is the ground reference, 7 is the soil near underground power cable, 8 is the $20 \mathrm{kV}$ underground power cable.

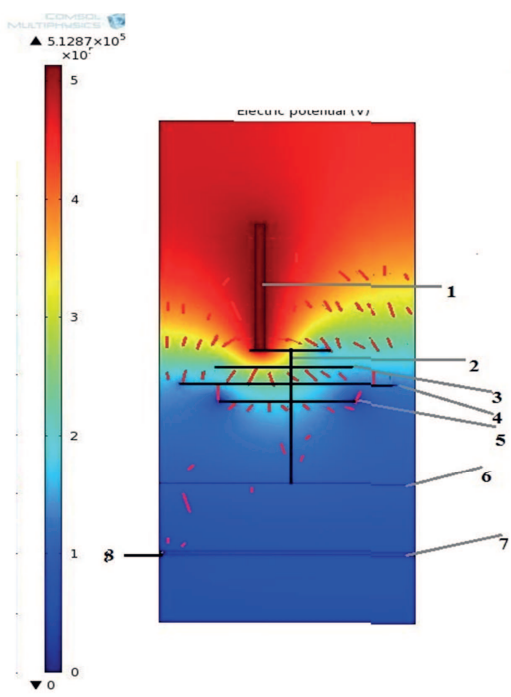

Fig. 7. Electric potential distribution when a direct lightning strike hits the tower structure of a $20 \mathrm{kV}$ overhead power line, for $8 / 20 \mu$ s lightning current wave shape, $t=0.003 \mathrm{~s}$

The results were analyzed in comparison with the ones from [25]-[26]. Two shots were captured for each lightning surge wave shape $(8 / 20 \mu \mathrm{s}$ and $5 / 320 \mu \mathrm{s})$ at $t=0.003 \mathrm{~s}$ of the AC voltage wave (Fig. 8).

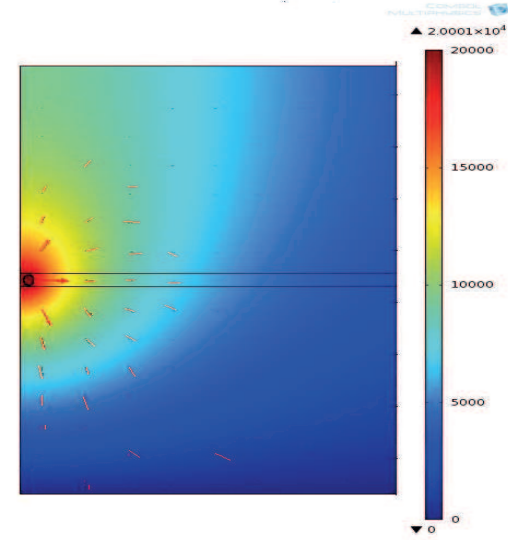

a)

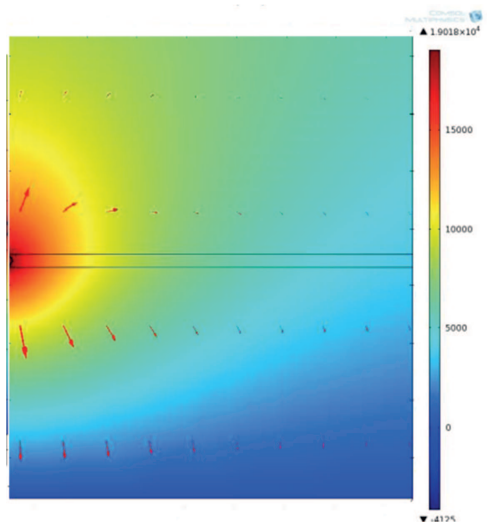

b)

Fig. 8. Electric potential distribution around underground power cable for a peak lightning current of $2.5 \mathrm{kA}$, coresponding to the surge voltage wave shape of a) $1.25 / 50 \mu \mathrm{s}$; b) $10 / 700 \mu \mathrm{s}$ 
Table $V$ and Table VI represent the maximum values of the electric potential, for different lightning current peak values (kA) and shapes $(8 / 20 \mu$ s and 5/320 $\mu$ s.

\section{Table V}

Maximum values of electric potential in $\mathrm{kV}$ for $8 / 20 \mu$ s lightning current in $\mathrm{kA}$

\begin{tabular}{|l|l|l|l|l|l|}
\hline Location & Description of location & $I_{p}=2.5$ & $I_{p}=6.5$ & $I_{p}=13$ & $I_{p}=40$ \\
\hline EP1 & Within power line phases & 200 & 425 & 1382 & 3400 \\
EP2 & Near ground & 71 & 223 & 510 & 1733 \\
EP3 & Near underground power cable & 22 & 75 & 171 & 656 \\
\hline
\end{tabular}

\section{Table VI}

Maximum values of electric potential in $\mathrm{kV}$ for $5 / 320 \mu$ s lightning current in $\mathrm{kA}$

\begin{tabular}{|l|l|l|l|l|l|}
\hline Location & Description of location & $I_{p}=2.5$ & $I_{p}=6.5$ & $I_{p}=13$ & $I_{p}=40$ \\
\hline EP1 & Within power line phases & 187 & 218 & 1323 & 3190 \\
EP2 & Near ground & 59 & 64 & 744 & 1313 \\
EP3 & Near underground power cable & 14 & 51 & 131 & 351 \\
\hline
\end{tabular}

\subsection{Dependency of electric field intensity on lightning current and soil resistivity}

The electric field intensity near underground cable was calculated, according to [27]-[28], for the case when the soil resistivity varies between $\rho=100-1000 \Omega \mathrm{m}$ and the installation depth of the cable is $-0.8 \mathrm{~m}$, with the relationship:

$$
E_{S}(r)=\rho_{s} \cdot \frac{I_{p}}{2 \pi r^{2}}
$$

where $I_{p}$ is the lightning current discharges through the ground, and the intensity of electric field $\boldsymbol{E}$ is calculated in the soil at a radius $r$ from the strike point (Fig. 9).

\section{Conclusions}

Simulations show that the effect of lightning surge propagation through underground structures is strongly dependent by the lightning channel parameters like length, current, wave shape. It is shown that the $8 / 20 \mu$ s lightning wave induces high surges than in the case of $5 / 320 \mu \mathrm{s}$. It was highlight that the soil resistivity has a great influence on the electric potential variation, as for the soils with resistivity higher than $500 \Omega \mathrm{m}$, are more exposed to high electric potentials variations. High electric fields generated by lightning near ground reference can cause electric potential rise in low voltage networks/ residential buildings. Of great importance is the rise of the ground electrodes resistance, which can affect the earth connection of low/medium voltage networks, especially in the case of the IT connections. 


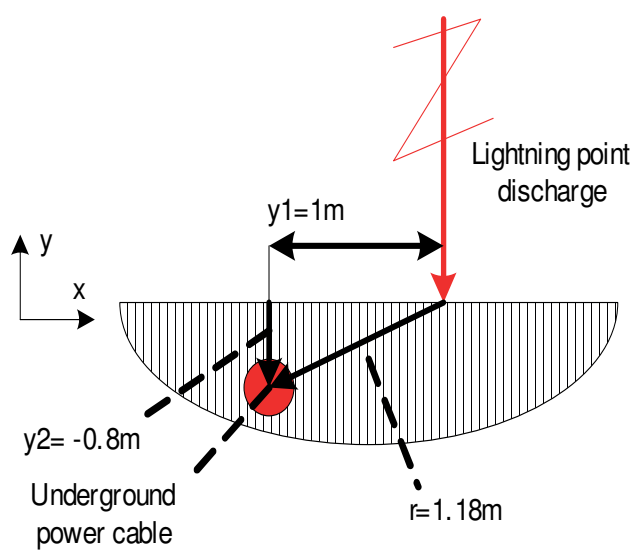

a)

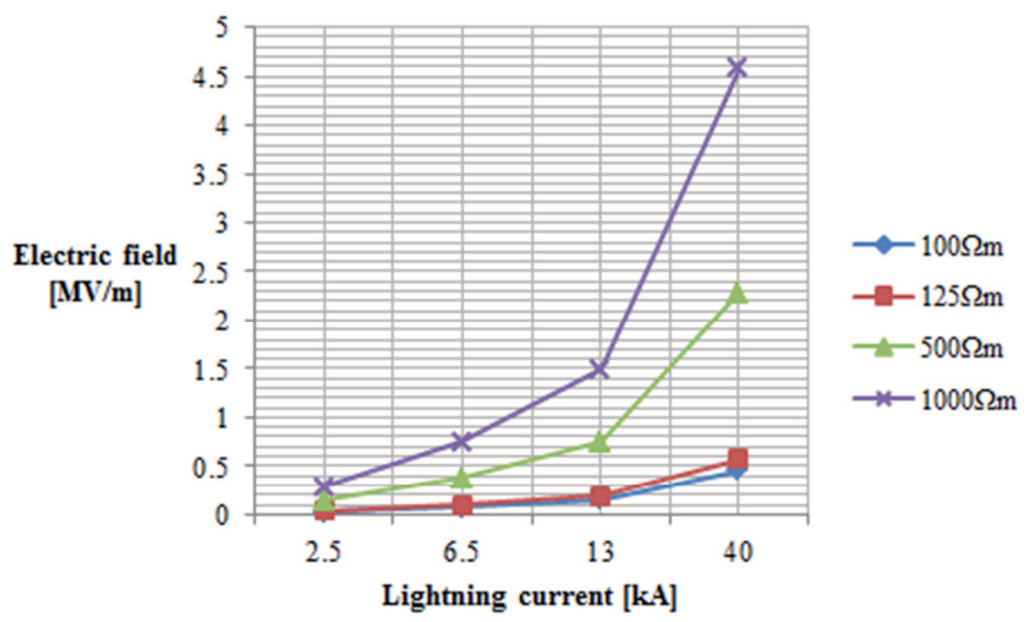

b)

Fig. 9. Dependency of electric field intensity on lightning current and soil resistivity a) Scketch for the case stady; b) Electric field intensity dependency on the peak lightning current for different soil resistivities

\section{Acknowledgements}

This paper is supported by the Sectoral Operational Programme Human Resources Development (SOP HRD), financed from the European Social Fund and by the Romanian Government under the project number POSDRU/159/1.5/S/134378. 


\section{References}

[1] De Conti S. V. Evaluation of lightning surges transferred from medium voltage to low voltage networks, IEE Proc. Gener. Transm. Distrib, Vol. 152, 2005, pp. 351-356.

[2] Hoidalen H. Kr. Lightning induced voltages in low-voltage systems and its dependency on overhead line terminations, Proc. of the $24^{\text {th }}$ International Conference on Lightning Protection, Seatle, Washington, 22-26 June 1997, pp. 287-292.

[3] Miyazaki T., Okalse S. A field study of lightning surge propagating into residences, IEEE Transactions on Electromagnetic Compatibility, Vol. 52, 2010, pp. 921-928.

[4] Rakotomalala A., Rousseau A. Lightning distribution through earthling systems, IEEE International Symposium on Electromagnetic Compatibility, Chicago, IL, 22-26 August 1994, pp. 419-423.

[5] Randolph J. Introduction to lightning and AC power fault surge protection for telecom signaling cables, IEEE Symposium on Product Compliance Engineering Portland, OR, 5-7 November 2012, pp. 1-11.

[6] Vintan M. About the coupling factor influence on the ground fault current distribution on overhead transmission lines, Advances in Electrical and Computer Engineering, Vol. 10, 2010, pp. 43-47.

[7] Schoene J. D. Direct and nearby lightning strike interaction with test power distribution lines, Doctoral Thesis, University of Florida, 2007.

[8] Lingvay I., Ciogescu O., Linvay C., Homan C. The degradation by corrosion of ground plates from the energetic system, Electrotehnica, Electronica, Automatica, Vol. 54, 2006, pp. 26-30.

[9] Rahimian M. S., Sadeghi S. H. H., Moini T. LEMP Coupling with medium voltage overhead line and its effects on low voltage networks with power electronic devices, $3 r d$ International Symposium on Electromagnetic Compatibility, China, 21-24 May 2002, pp. $115-118$.

[10] Hoidalen H. Kr., Sletbak J., Hewriksen T. Ground effect on induced voltages from nearby lightning, IEEE Transact. on Electromagnetic Compatibility, Vol. 39, 1997, pp. 269-278.

[11] Tsiammitros D. A., Christoforidis G. C., Papagiannis G. K., Labidis D. P., Dokopoulos P. S., Earth conduction effects in systems of overhead and underground conductors in multilayered soils, IEE Proc. Gener. Transm. Distrib, Vol. 153, 2006, pp. 291-299.

[12] Papagiannis G. K., Tsiammitros D. A., Labidis D. P., Dokopoulos P. S., Direct numerical evaluation of earth return path impedances of underground cables, IEE Proc. Gener. Transm. Distrib, Vol. 152, 2005, pp. 321-327.

[13] Rakov V. A., Rachidi F. Overview of recent progress in lightning research and lightning protection, IEEE Transactions on Electromagnetic Compatibility, Vol. 51, No. 3, 2009, pp. 429-442.

[14] Paulino J. O. S., Barbosa C. F., Lopes I. J. S., Boaventura W. C. An approximate formula for the peak value of lightning-induced voltages in overhead lines, IEEE Transactions on Power Delivery, Vol. 25, No. 2, 2010, pp. 843-851.

[15] Martinez J. A., Aranda F. C. Tower modeling for lightning analysis of overhead transmission lines, Proc. Power Engineering Society General Meeting, San Francisco, 12-16 June 2005, pp. 1-6.

[16] Goni O., Hossain F., Yusuf S. U., Rahman M., Kaneko E., Takahashi H. Simulation and experimental analyses of electromagnetic transients behaviors of lightning surge on vertical conductors, IEEE Transactions on Power Delivery, Vol. 21, 2006, pp. 1778-1786.

[17] Brochure CIGRE Working Group, C4.501/2013 - Guideline for numerical electromagnetic analysis method and its application to surge phenomena, CIGRE Technical, 2013. 
[18] Ianoz M. Review of new developments in the modeling of lightning electromagnetic effects on overhead lines and buried cables, IEEE Transactions on Electromagnetic Compatibility, Vol. 49, No. 2, 2007, pp. 224-236.

[19] Izadi M., Zainal M., Hajikhani M. Ground reflection effect on the lightning electromagnetic fields, Proc. of $22^{\text {nd }}$ International Conference on Electricity Distribution, Stockholm, 10-13 June 2013, Paper 0449.

[20] Packnahad J., Sheshyekani K., Hamzeh M., Rachidi F. Lightning electromagnetic fields and their induced voltages on overhead lines: the effect of a non-flat lossy ground, Proc. of International Conference on lightning protection, Shanghai, 11-18 October 2014, pp. 591-594.

[21] Lightning protection guide, 2nd updated edition, Dehn and Söhne Gmb, 2007.

[22] EN 61000-4-4, Testing and measuring techniques, Electric fast transient/burst immunity test, 2011.

[23] EN 61000-4-5, Testing and measuring techniques, Surge immunity test, 2013.

[24] Heidler F., Cvetic J. A class of analytical functions to study the lightning effects associated with the current front, European Transactions on Electrical Power, Vol. 12, 2002, pp. $141-150$

[25] Marcsa D., Kuczmann M. Parallel solution of an electrostatic field problem-case study, Pollack Periodica, Vol. 7, 2012, pp. 25-34.

[26] Uribe F. A. Mutual ground impedances between overhead and underground transmission cables, International Conference on Power Systems Transients, Montreal, Canada, 19-23 June 2005, pp. 1-6.

[27] Omidiora M. A., Lehtonen M. Simulation performance of lightning discharges around medium voltage underground cables, Proceedings of the 44th International Universities Power Engineering Conference (UPEC), Glasgow, 1-4 September 2009, pp. 1-5.

[28] Yaqing L., Zitnik M., Thottappillil R. An improved transmission-line model of grounding system, IEEE Transactions, on Electromagnetic Compatibility, Vol. 43, 2001, pp. 348-355. 